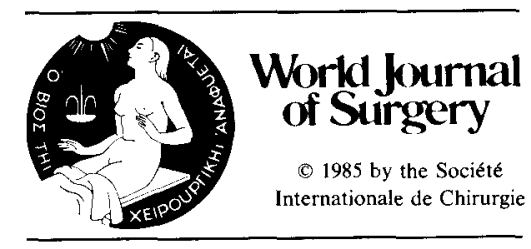

\title{
New Surgical Approaches to Ulcerative Colitis in Children and Adults
}

\author{
Arnold G. Coran, M.D. \\ Section of Pediatric Surgery, The University of Michigan Medical School and the Mott Children's Hospital, \\ Ann Arbor, Michigan, U.S.A.
}

Ulcerative colitis continues to be a devastating disease for the child and the young adult. In spite of intensive medical therapy with sulfasalazine and corticosteroids, the majority of patients with universal ulcerative colitis will ultimately require a total colectomy. The standard operation of a total proctocolectomy and a permanent end ileostomy is probably still the best procedure for the definitive management of this disease because all diseased tissue is removed with this operation; however, the resultant abdominal stoma can create significant psychological trauma in many of these patients. For that reason, sphincter-saving operations were introduced in 1933 but were only marginally successful until 1977, when renewed interest in the endorectal pullthrough occurred. Since that time, several centers around the world have gained significant experience with the endorectal procedure, with or without the use of an ileal reservoir. Although the ileal reservoir appears to have certain advantages over the straight endorectal pullthrough, the procedure also is associated with a significant number of complications and is a far more complicated technical exercise.

The experience at the University of Michigan with the straight endorectal pullthrough procedure in patients with ulcerative colitis and familial polyposis during the period from 1977 to 1984 is herein reported. All of the patients in our series are continent and experience a median stool frequency of 6 per 24 hours 1 year after the procedure. Patient satisfaction has been excellent with the majority of patients preferring their lifestyle without an ileostomy to that experienced with an ileostomy. At the present time, we can strongly recommend the endorectal pullthrough procedure to all patients with ulcerative colitis.

Reprint requests: Arnold G. Coran, M.D., Head of the Section of Pediatric Surgery, Mott Children's Hospital, Room F7516, Box 66, Ann Arbor, Michigan 48109, U.S.A.
Ulcerative colitis was first described in 1859 by Sir Samuel Wilkes, pathologist and physician at Guy's Hospital in London. However, no attempt to treat the disease in either its acute or chronic phases was made until 1902, when Weir performed a tube appendicostomy [1]. The first ileostomy for acute ulcerative colitis was performed in 1913 [2]. Ileostomy became the procedure of choice for the management of ulcerative colitis until 1948 when Cattell recommended a 3-stage operation consisting of an initial ileostomy, followed by a subtotal colectomy with exteriorization of the sigmoid mucous fistula and a subsequent abdominoperineal resection of the rectum [3]. Shortly thereafter, the operation was modified to a 2-stage one in which an initial ileostomy and subtotal colectomy were followed by a subsequent abdominoperineal resection of the rectum. Goligher, in 1952, introduced a one-stage operation consisting of an end ileostomy and a total proctocolectomy [4]. The eversion technique of ileostomy construction, introduced by Brooke in 1952, markedly improved ileostomy management and made the operation of total proctocolectomy far more attractive to patients with ulcerative colitis [5].

As a result of continuing interest in continencepreserving operations for ulcerative colitis, other procedures were introduced in the 1960s. Aylett of Britain advocated sparing the rectum by constructing an ileorectostomy after an abdominal colectomy [6]. Most surgeons do not use this operation because it leaves behind the diseased rectum which ultimately requires removal due to poor results or risk of rectal carcinoma.

Another approach to continence-preserving surgery was taken by Koch of Sweden who introduced the continent ileostomy [7]. This procedure involved the construction of an intra-abdominal ileal 
reservoir and a nipple-valve which usually makes an external appliance unnecessary. Since that time hundreds of patients have undergone this procedure and have greatly benefited from it [8-16]. Ninety to ninety-five percent of patients with a continent ileostomy are able to function without an external appliance and appear to be enthusiastic about this operation. However, the operation is complex and is associated with a number of complications. Most importantly, however, an abdominal stoma is still necessary.

As a result of continuing interest in finding an operation for ulcerative colitis which definitively treats the disease and eliminates the need for an abdominal stoma, sphincter-saving operations have been sought extensively during the past 50 years. Nissen was the first surgeon to perform an ileoanal anastomosis in 1933 [17]. The operation was unsuccessful; however, the same procedure was subsequently tried by Wangensteen in 1943, again without success [18]. In 1947, Ravitch and Sabiston described the technique of rectal mucosectomy and endorectal ileal pullthrough in dogs [19]. Since they had success with this operation in the experimental animals, the authors applied this technique to 5 patients with ulcerative colitis and 4 with familial polyposis $[20,21]$. Two of their 9 patients required reconstitution of their ileostomy; however, the other 7 patients appeared to do generally well following their operation.

By 1960 , forty-one patients had undergone an endorectal ileal pullthrough [22-30]. Of these 41 patients, $22(54 \%)$ were continent and $15(37 \%)$ required a subsequent permanent ileostomy. Between 1960 and 1977, the operation was used with minimal enthusiasm and with marginal results. During this period, 35 patients underwent an endorectal ileal pullthrough following a colectomy and $77 \%$ of these were continent; $7 \%$ required conversion to a permanent ileostomy $[18,27,31-36]$.

Interest in the endorectal pullthrough was renewed in 1977 when Martin reported his experience with 17 teenagers [37]. Fifteen of these patients did quite well following the procedure; only 2 required reconstitution of their abdominal ileostomy. By February 1984, several authors had reported the results of their clinical experience with the endorectal pullthrough for ulcerative colitis and familial polyposis; approximately 300 such operations were reported at that time [37-45].

\section{Indications for Operation}

Americans who have inflammatory bowel disease number between 200,000 and 400,000 . Fifteenthousand to 30,000 new cases are diagnosed each year and $20 \%$ of the patients are less than 20 years old. Although a substantial number of patients with ulcerative colitis never require operation for their disease, many ultimately require a definitive surgical procedure. The medical management of ulcerative colitis is aimed at relieving symptoms. Although corticosteroids and sulfasalazine sometimes induce complete remission and even cure of ulcerative colitis, this happens relatively infrequently.

Our indications for surgery are (a) persistent signs of disease after 2 years of adequate medical therapy including sulfasalazine and corticosteroids; (b) inability to wean the patient from high-dose corticosteroid therapy; (c) growth retardation or delay in the development of secondary sex characteristics secondary either to the disease itself or to the corticosteroid therapy; and (d) the risk of carcinoma of the colon in patients with longstanding ulcerative colitis. The incidence of carcinoma of the colon is about $3 \%$ during the first decade of the disease and, thereafter, increases at the rate of $20 \%$ per decade [46, 47]. The carcinomas arising in ulcerative colitis tend to be multiple and much flatter than classical carcinoma of the colon, making their radiologic detection more difficult. Moreover, they tend to be mucin-secreting and anaplastic, carrying a much poorer prognosis than in standard carcinoma of the colon. For these reasons, we recommend a total colectomy for anyone who has had universal ulcerative colitis longer than 10 years. Less common indications for surgery are unremitting hemorrhage and free perforation of the colon.

\section{Surgical Techniques for Performing the Endorectal Pullthrough}

The patient is positioned for a combined approach to the abdomen and perineum. Through a vertical incision, the entire colon from the cecum to the rectum is removed and the terminal ileum is mobilized so that adequate length and blood supply are obtained. Differences of opinion exist as to the best approach to the rectal mucosectomy. Some authors $[37,44]$ prefer to do the entire mucosal stripping from the abdominal approach; others, however, feel that the mucosal stripping is performed much more easily from the perineal approach $[38,48]$. If the abdominal approach is used, the entire mucosalsubmucosal tube is dissected out and then everted outside the anal opening as an intact tube. When the perineal approach is utilized, the rectum is dissected down to the level of the levator muscles, staying close to the wall of the intestine to minimize damage to the nerve supply of the bladder and the genitalia. Following this, the rectal mucosectomy is then performed by incising the rectal mucosa at the level of the dentate line and then freezing it up by 
both blunt and sharp dissection circumferentially to the level of the levator musculature.

If a straight endorectal pullthrough is being performed, the terminal ileum is then brought down through the rectal muscular cuff and is anastomosed to the dentate line with interrupted absorbable sutures. At the end of the procedure, a loop ileostomy is constructed in the right lower quadrant for intestinal diversion.

If an ileal reservoir is to be used, 3 types of procedures have recently been recommended: (a) the $J$-loop, as first described by Dimitriu [49] and later modified by Utsunomiya [42], (b) the $S$-shaped or sigmoid-shaped reservoir as initially described by Parks and Nicholls [39] and later reported by Martin and Fischer [50], and (c) the lateral isoperistaltic ileal reservoir as described by Peck [41] and Fonkalsrud [51].

If the endorectal dissection is done gently and meticulously, then anal incontinence should not result. We can define anal continence as the ability to defer defecation voluntarily, to identify the quality of rectal contents, and to maintain control nocturnally. There are several physiological interactions required to achieve normal anorectal continence. These include the anorectal angle, the volume and consistency of the stool, the anal sphincters, the anal and rectal sensory mechanisms, and the reservoir capacity and compliance of the rectal ampulla. Stephens and Smith [52] and Kiesewetter and Nixon [53] found that the puborectalis muscle is largely responsible for continence after surgical repair of imperforate anus. The anal sphincters maintain closure of the anal canal and thus allow fecal material to be built up in the rectal ampulla. In this way, the rectal ampulla acts as a reservoir and maintains low intrarectal pressures. When rectal distention reaches a certain point, a reflex is triggered by receptors in the rectal wall or in the perirectal musculature of the pelvis which causes the internal sphincter to relax and allows the rectal contents to come in contact with the sensitive anal canal thus initiating the urge to defecate $[29,54-61]$.

After the endorectal pullthrough procedure, the anorectal angle should be maintained because the puborectalis muscle and the levator muscle complex are undisturbed since the entire dissection is performed within the rectal muscular cuff. In addition, all the anal sphincters should be intact after the operation, once again because the dissection is entirely done within the rectal muscular cuff. Continence may, however, be affected by the liquidity of the stool and the frequency of stooling, even though all of the physiological mechanisms for continence are present.

\section{Recent Experience with the Endorectal Pullthrough}

In 1978, Von Ekesparre and Janneck reported their experience with 6 patients with ulcerative colitis who remained continent 7 to 12 years after the endorectal pullthrough [62]. At that time, 6 other patients with familial polyposis who had undergone an endorectal pullthrough were reported by various authors; all were continent postoperatively in spite of several complications [63-65]. In 1980, Fonkalsrud reported his experience with the endorectal pullthrough using an $S$-shaped ileal reservoir in 5 patients [40]. There was only moderate success with this initial series of patients. Parks and associates reported on their experience with 22 patients, in 1980, in whom an $S$-shaped ileal reservoir was used together with an endorectal pullthrough [39, 66]. Twenty of the 22 patients were continent; however, one-half of these patients had to intubate their pelvic pouch in order to empty it.

Peck described his experience with 29 patients with familial polyposis and chronic ulcerative colitis in whom ileal grafts were placed into the rectal muscular cuffs following rectal mucosal stripping [41], a technique previously reported by Glotzer and associates [67]. Four of the 29 patients were incontinent postoperatively and 2 subsequently required reconstitution of their ileostomy.

Utsunomiya presented his experience with the $J$-pouch, which he performed on 6 young adults in 1980 [42]. All 6 patients were continent postoperatively and appeared to have around 5 stools per day. In 1981, Telander and Perrault $[43,48]$ updated their earlier experience and reported on 25 children and young adults who had undergone an endorectal ileo-anal anastomosis. These patients were treated with a straight endorectal pullthrough without reservoir. Twenty-four patients were continent during the day but 2 experienced incontinence at night. Two patients eventually required revision of their ileo-anal anastomosis and conversion to an abdominal ileostomy, one because of active Crohn's disease in the rectal cuff segment of the ileum, the other because of persistent discomfort in the perineum. No pelvic sepsis was seen in this group in contrast with the previously reported series. In these patients, the authors used gradual balloon dilatation of the pulled-through ileum in order to achieve an increased reservoir capacity of the neorectum. This balloon dilatation significantly decreased the stool frequency during the first year after surgery.

Of the 123 patients operated on between 1977 and 1981, intestinal continuity was re-established in 110 . One hundred of these $(91 \%)$ were continent. Nine patients $(8 \%)$ required reconstitution of their ileostomy. Thus 209 patients underwent total colec- 
tomy and endorectal ileo-anal anastomosis for ulcerative colitis or familial polyposis between 1933 and 1981. Eight (4\%) died of postoperative complications, $80 \%$ were continent, and $14 \%$ required revision to a permanent abdominal ileostomy [68].

During the last 2 years, 7 major series have been reported. Martin and Fischer updated their experience with 37 patients [50]. The first 19 underwent a straight endorectal pullthrough. The last 18 underwent a pullthrough with an $S$-shaped reservoir. All of the last 18 patients treated with a reservoir were continent and did not experience excessive stool frequency. Likewise, Rothenberg and colleagues reported their experience with 29 patients who underwent an endorectal pullthrough together with an $S$-shaped ileal reservoir [45]. Twenty-four of these 29 patients had had their temporary loop ileostomy closed and were available for postoperative evaluation. Four of these 24 experienced intermittent incontinence during the day or at night. The stool frequency in this group was between 2 and 11 with an average of 6 . A significant number of complications such as pouchitis, ileo-anal stricture, perirectal abscess, and intestinal obstruction was reported in this series.

Handelsman and associates recently described their experience in 15 adults with ulcerative colitis and familial polyposis who underwent an endorectal pullthrough [69]. Two of the patients had a straight endorectal pullthrough, 11 underwent an $S$-shaped reservoir, and in 2, a $J$-pouch was constructed. Incontinence was seen in only 2 of these patients, both of whom had undergone a reservoir procedure. The 2 patients who underwent the straight endorectal pullthrough experience 6 to 8 bowel movements per day, whereas the patients with reservoirs were having 3 to 6 movements per 24 hours. None of the patients in this series with an $S$-shaped reservoir required intubation of the reservoir for evacuation as opposed to the experience of Rothenberger et al. [45] in which pouch evacuation with a catheter was required in 8 of their 24 patients.

Heimann and associates detailed their experience with 19 patients last year [70]. All of these patients underwent a straight endorectal pullthrough without reservoir. In 17 of the 19 patients the temporary loop ileostomy has been closed. All of their patients were continent postoperative, and experienced a mean of 6 bowel movements per 24 hours. Their complication rate was extremely low in comparison with other reported series.

We reported our initial experience with the endorectal pullthrough for ulcerative colitis in children and adults in January 1983 [44]. We performed the straight pullthrough in 26 patients with good results and few complications, consisting of 3 cases of intestinal obstruction, 1 rectal cuff abscess, and a retroperitoneal abscess. All the patients were continent postoperatively and they experienced a median stool frequency of 7 per 24 hours 1 year after surgery. Our updated series will be presented in the next section.

The largest reported series thus far is from the Mayo Clinic [71]. In June 1983 they reported their collected experience with 124 patients. They compared the postoperative results in 50 patients who underwent the straight ileo-anal anastomosis after total colectomy and mucosal protectomy with those in 74 patients who had an ileal pouch-anal anastomosis. They utilized the $J$-pouch for their reservoir. There were no deaths in the series. Of the straight ileo-anal anastomoses, $32 \%$ failed because of sepsis or diarrhea and necessitated an abdominal ileostomy; only $1.3 \%$ failed in the pouch-anal group. The stool frequency was 11 per day 18 months after the straight endorectal pullthrough and 7 per 24 hours 6 months after the $J$-pouch procedure.

In February 1984, Fonkalsrud updated his entire experience with the endorectal pullthrough and the isoperistaltic ileal reservoir [38]. He performed this operation in 45 patients with ulcerative colitis and familial polyposis. Thirty-eight of the 45 patients had undergone the lateral ileal reservoir construction at the time of the report and 33 had achieved a good to excellent result with complete continence and an average stool frequency of 5 per 24 hours 6 months after the operation. Half of the patients, however, experienced transient or longstanding reservoir inflammation postoperatively.

During this same 2-year period, a small series was reported from Australia by Roediger et al. [72]. They related their experience in 6 patients with ulcerative colitis who had undergone a subtotal colectomy, a mucosal protectomy, and a coloanal anastomosis with preservation of the ascending colon. The results were quite good with a stooling pattern of 3 to 4 every 24 hours.

\section{University of Michigan Experience}

Our interest in the endorectal pullthrough began in 1970 when we utilized it for the management of classical rectosigmoid Hirschsprung's disease [73, 74]. As a result of our early success with this operation, we employed it in 1974 for the definitive treatment of total colonic aganglionosis. We used the procedure in 6 children with total colonic Hirschsprung's disease and were impressed with the postoperative results. All 6 are totally continent and are having 2 to 3 formed bowel movements per day [75].

In view of these results, we were encouraged to utilize this same procedure in children and adults 
with ulcerative colitis and familial polyposis beginning in 1977. Our initial experience with the pullthrough in 26 children and adults with ulcerative colitis was reported in January 1983 [44]. To date the operation has been performed in 48 children and adults with ulcerative colitis and familial polyposis, 47 of whom have had their temporary ileostomy closed.

There are 20 males and 28 females in the series with ages ranging from 7 to 46 years at the time of operation. All patients underwent an air contrast barium enema and a small bowel radiography series, and, in every case, the barium enema was characteristic of ulcerative colitis or familial polyposis. The small bowel series was entirely normal in all patients with ulcerative colitis except one, in whom lymph node hypertrophy in the terminal ileum was noted. The duration of medical management for ulcerative colitis, which in all cases consisted of varying and intermittent courses of sulfasalazine and corticosteroids, ranged from 1 to 22 years.

Nineteen of 41 patients with ulcerative colitis underwent a subtotal colectomy because of either severe rectal bleeding or worsening symptoms in the face of maximal doses of corticosteroids and complete bowel rest with total parenteral nutrition. The other 22 patients had an elective colectomy together with a mucosal protectomy and a loop ileostomy. The 19 patients who underwent an initial subtotal colectomy, ileostomy, and mucous fistula of the sigmoid colon returned to the hospital for endorectal pullthrough about 3 to 6 months after the initial operation. All patients were restricted to a clear liquid diet 48 hours prior to surgery. Oral erythromycin and neomycin were administered the day prior to surgery and irrigations of $1 \%$ neomycin were given through the mucous fistula during the same period in those patients who had undergone a previous subtotal colectomy. Patients with intact colons received tap-water enemas during the 48hour period prior to surgery. Broad-spectrum antibiotics were given parenterally the night prior to surgery and on-call to the operating room. These parenteral antibiotics were continued for 5 days following surgery. Sigmoidoscopy was carried out 1 week prior to the pullthrough procedure in order to determine the state of the rectal inflammation. If significant inflammation was present, the operation was delayed and the patient was treated with steroid enemas with or without bowel rest and total parenteral nutrition. Six of the 7 patients with familial polyposis underwent an initial operation consisting of a colectomy, a mucosal protectomy, an ileo-anostomy, and a loop ileostomy. Four of these 6 patients had undergone a previous subtotal colectomy several years prior to the pullthrough

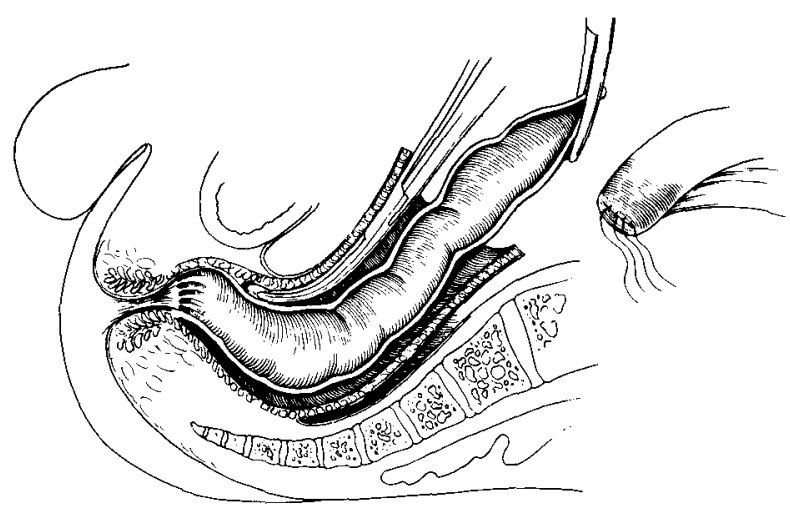

Fig. 1. The endorectal dissection is carried out between the submucosa and muscularis of the rectum.

and had been subjected to multiple fulgurations of the rectum for persistent polyps. One recent youngster underwent a total colectomy, a mucosal proctectomy, and an ileo-anostomy without an ileostomy.

The operation is performed with the patient in the lithotomy position for a combined approach to the abdomen and perineum. We prefer the popliteal rests rather than the stirrups for the legs since these allow better exposure of the abdominal and perineal fields. Sigmoidoscopy is carried out and the liquid material in the rectum and sigmoid colon is thoroughly suctioned out. The abdomen and perineum are draped as one field. A Foley catheter is inserted into the bladder prior to preparation of the field. The abdomen is entered through a long left lower adominal paramedian incision. The entire colon is mobilized down to the level of the midsigmoid and a standard subtotal colectomy is carried out. The terminal ileum is closed with several long sutures of 3-0 silk. If a previous subtotal colectomy had been carried out, the mucous fistula which usually has been placed at the lower end of a left paramedian incision, is mobilized from the incision once the abdomen is open. The ileostomy, in this situation, is not taken down until it is determined that an endorectal dissection is feasible. The endorectal dissection is begun by incising the seromuscular layer of the rectum at its peritoneal reflection. This incision is carried around the rectum and a plane is developed between the submucosa and the muscularis. The dissection is continued bluntly and sharply in this plane all the way down to the anus from the abdominal approach (Fig. 1). There are many large blood vessels running along the submucosa and these must be cauterized during the dissection to prevent excessive blood loss. Early in this series, 3 units of blood were often required to complete the operation because of the blood loss encountered during the endorectal dissection. More recently, no blood transfusion has been given dur- 


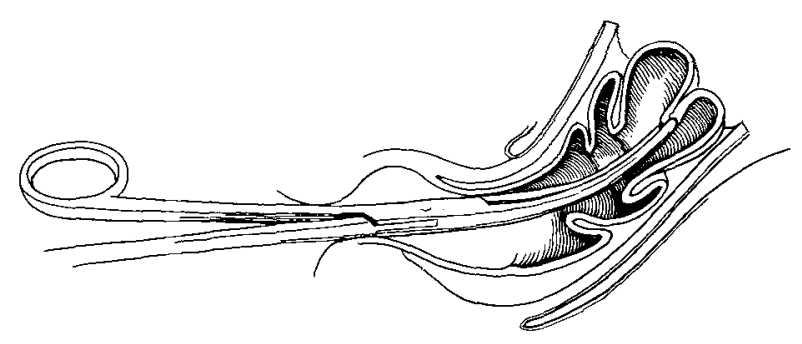

Fig. 2. The rectal mucosal-submucosal tube is everted outside the anal opening.

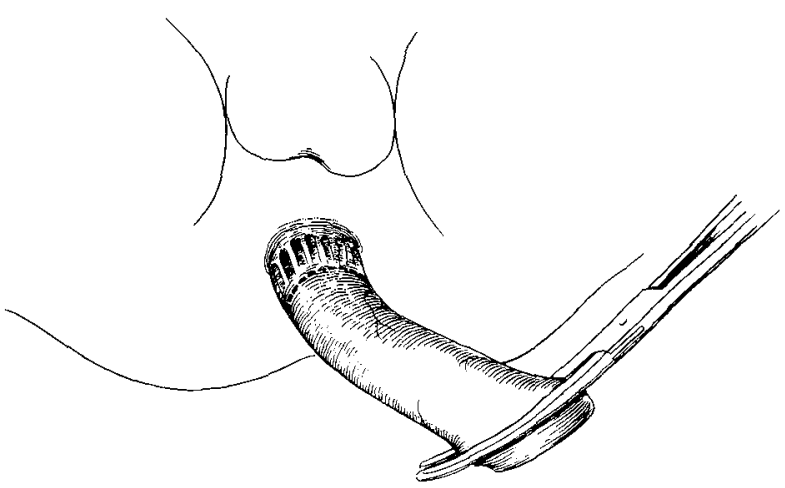

Fig. 3. The everted mucosal-submucosal tube is incised anteriorly at the pectinate line.

ing the operation. Even in the adult, the endorectal dissection can be completely performed from the abdominal approach in almost all cases. Occasionally, in the case of an adult male with a deep android pelvis, the dissection has to be completed from the perineum. However, this is the exception rather than the rule. Once the dissection has been completed, the top of the rectal mucosal-submucosal tube is grasped with a long clamp and is everted outside the anal opening (Fig. 2). At this point, the mesentery of the terminal ileum is incised for a reasonable distance so that the small bowel can be brought down to the anus without tension. If an ileostomy is in place, it is taken down at this point. With traction on the everted mucosal-submucosal tube, an incision is made just proximal to the pectinate line for a distance of $180^{\circ}$ (Fig. 3). A clamp is placed through this incision and is passed up through the rectal cuff in order to grasp the sutures on the terminal ileum (Fig. 4). The ileum is brought down to the opening in the everted tube and a similar incision on the anterior half of the ileum is created (Fig. 5). An anastomosis is now formed between the anorectal mucosa and the fullthickness of ileum with interrupted sutures of 3-0 or 4-0 Vicryl ${ }^{\circledR}$ (Fig. 6). A third quadrant of the pulledthrough ileum and the everted tube is cut and the anastomosis is continued (Fig. 6). After the anastomosis of the third quadrant is completed, the re-

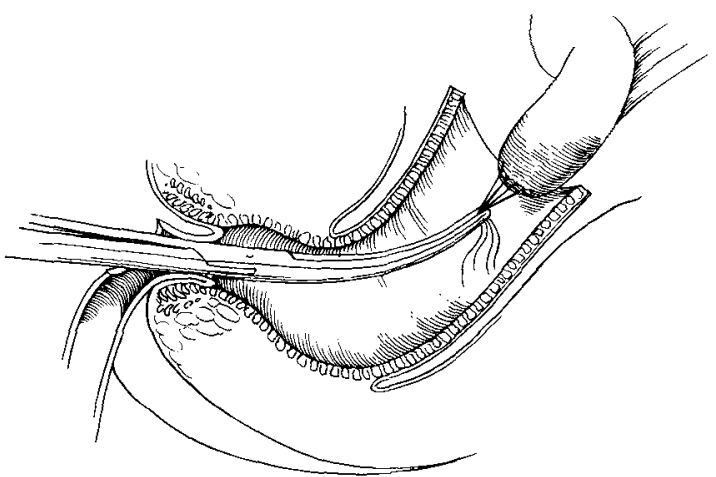

Fig. 4. A clamp is passed through the opening in the everted tube in order to grasp the terminal ileum.

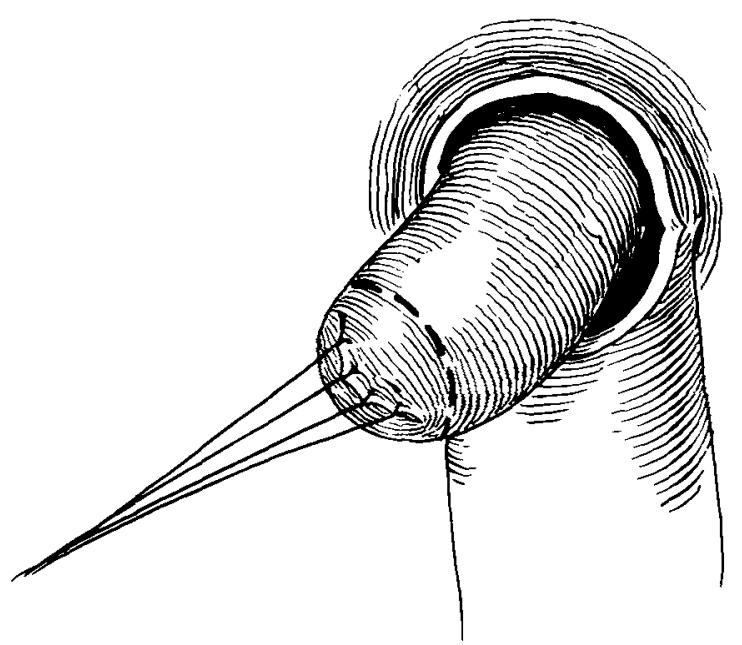

Fig. 5. The anterior wall of the terminal ileum is incised.

mainder of the everted tube and the distal portion of the ileum are excised and the anastomosis is completed with several more interrupted sutures. Before the last suture is placed, a small Silastic ${ }^{\circledR}$ sump drain is inserted between the rectal cuff and the pulled-through ileum (Fig. 7). The top of the rectal cuff is usually removed for a distance of $2-4 \mathrm{~cm}$ prior to the ileal pullthrough so as to decrease the chance of kinking the mesentery of the ileum once it is placed in the cuff. After the ileo-anal anastomosis is completed, the top of the remaining rectal cuff is tacked to the pulled-through ileum with several interrupted sutures of 3-0 silk (Fig. 8). Next, a loop ileostomy is created just proximal to the pulledthrough ileum and is exteriorized in the right lower quadrant of the abdomen (Fig. 9). The ileostomy is tacked circumferentially to the peritoneum with interrupted sutures of 3-0 or 4-0 silk and a rod is fashioned around the ileostomy with a no. 24 rubber catheter that is sutured to itself. Once the abdomen is closed, the ileostomy is opened transversely in the operating room (Fig. 10). 


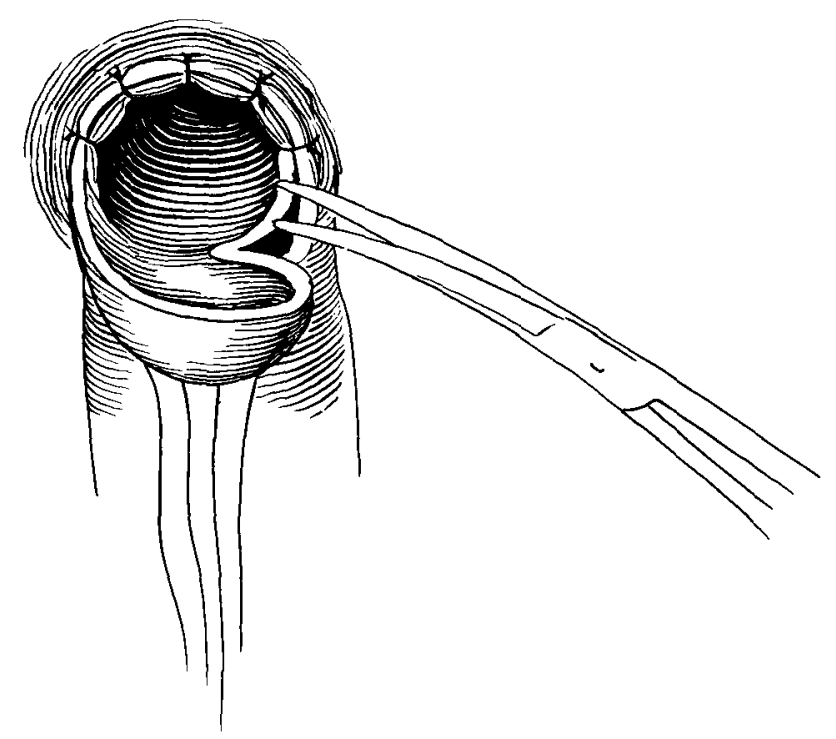

Fig. 6. An anastomosis is created between the terminal ileum and the anorectal mucosa.

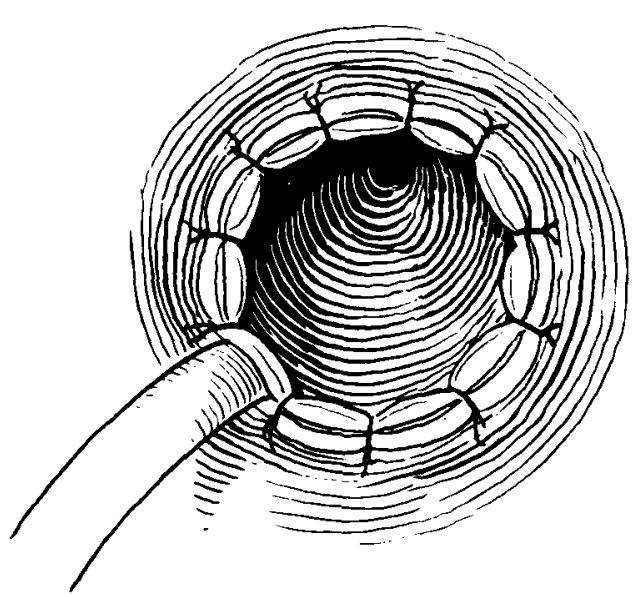

Fig. 7. The anastomosis is completed and a drain is left between the rectal cuff and the ileum.

Between the seventh and tenth postoperative day, a rectal examination is carried out to check the status of the anastomosis. At that time, the ileostomy rod is removed and the ileostomy is allowed to sink slightly below the skin so that spill over of fecal content will begin to occur, and the patient will start to experience the presence of semi-liquid feces in the new rectal ampulla. While the rod is in place, the ileostomy is totally diverting; this facilitates healing of the ileo-anal anastomosis. Two months after the endorectal pullthrough procedure, the patient is returned to the hospital for ileostomy closure. Under anesthesia prior to ileostomy closure, the pulled-through area is palpated and is dilated if necessary.

There was no mortality in this series and all

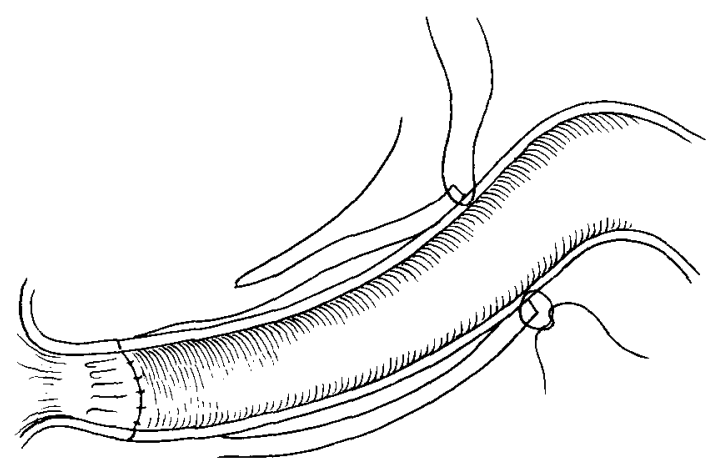

Fig. 8. The top of the rectal cuff is tacked to the ileum.

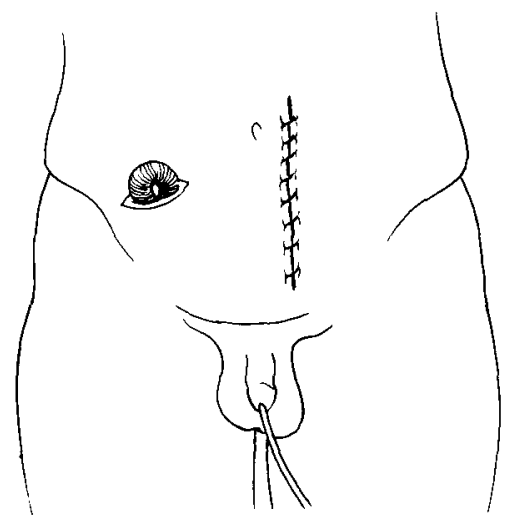

Fig. 9. A loop ileostomy is exteriorized in the right lower quadrant of the abdomen.

patients showed significant clinical improvement. Two patients underwent enterolysis for intestinal obstruction 1 week following ileostomy closure and 1 teenager underwent lysis of adhesions 1 year after surgery. The first patient in the series developed a small cuff abscess 3 weeks after ileostomy closure, which was treated with drainage and reconstitution of an ileostomy. A retroperitoneal abscess developed 1 year after the pullthrough; this was drained intraoperatively and caused no further problems. A rectovaginal fistula developed in a woman who had undergone a previous abdominal hysterectomy. This healed spontaneously and she is now awaiting ileostomy closure. All abdominal wounds were closed primarily and no wound infections were encountered.

All patients were continent during the day immediately after ileostomy closure and, with rare exceptions, were continent at night within a month after the ileostomy had been closed. Even during the first month after ileostomy closure, very few patients experienced any significant fecal soiling during sleep. The follow-up in these patients ranges from 5 months to 7 years and has been carried out personally by the author at least every 3 to 6 


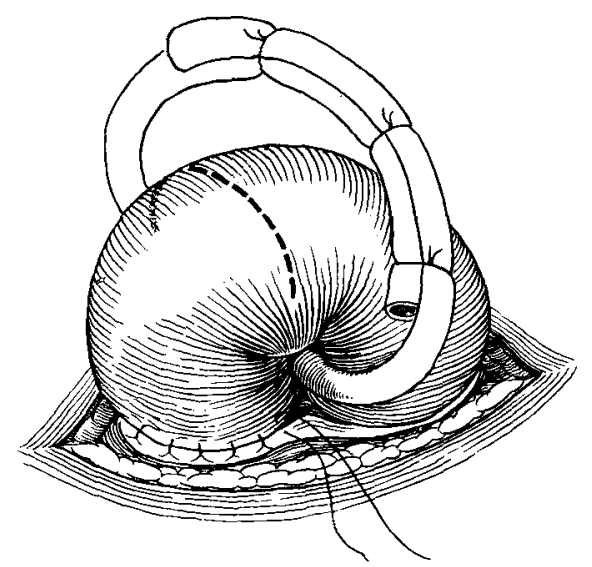

Fig. 10. The ileostomy is opened transversally.

months. One month after ileostomy closure the number of stools ranged from 2 to 20 per 24 hours. The stool frequency gradually decreased over the next 6 to 12 months so that at 1 year after ileostomy closure the median stool frequency was 6 per 24 hours. In addition, 1 year after operation, most patients were usually sleeping through the night and only a few had to awaken once or twice to move their bowels. Only 1 patient developed any significant perianal excoriation; this occurred in an adult male who was having between 10 and 15 semi-liquid bowel movements per day. After 1 year, this problem disappeared.

Although many of the patients require intermittent use of Metamucil ${ }^{\circledR}$, Lomotil ${ }^{\circledR}$, and Imodium $\left({ }^{\circledR}\right.$ (loperamide) during the first 6 to 12 months after surgery, only a small number require frequent use of these medications after 1 year.

Each patient was asked to compare his lifestyle with an ileostomy with that experienced after the ileostomy was closed. In all but 6 cases the patient preferred the increased stool frequency associated with the endorectal pullthrough to the presence of an abdominal stoma. Of these 6 patients, 1 adult female underwent a reconstitution of her ileostomy 3 weeks after its closure because of the development of a cuff abscess. An 8-year-old girl experienced severe diarrhea 5 months after ileostomy closure. This could only be managed by re-creation of a loop ileostomy. Subsequent biopsies of her ileum strongly suggested that her diagnosis was Crohn's disease rather than ulcerative colitis. The other 4 patients requested the reconstitution of an end ileostomy between 1 and 2 years after their pullthrough procedure because of persistent stool frequency of 10 to 15 per 24 hours, which they felt interferred with their lifestyle. These 4 patients were completely continent and were otherwise well. They are all considering the possibility of closing their ileostomy eventually.

The endorectal pullthrough procedure is ideally suited for the management of ulcerative colitis and familial polyposis since these diseases are limited to the mucosa. However, in each case, it is important that nearly all the rectal mucosa be removed during the procedure. The technique I have described, which involves an intact dissection of the entire musocal-submucosal tube from the abdominal approch with subsequent eversion of this tube prior to its excision, guarantees removal of all the diseased mucosa. The techniques in which the endorectal dissection is performed from the perineum run the risk of leaving behind diseased mucosa. Even if we have to complete the dissection from the perineum, we always do so with the subsequent removal of an intact mucosal-submucosal tube. We always leave behind a $1-\mathrm{cm}$ rim of distal mucosa because we feel this mucosa is important for the control of gas and liquid feces. Therefore, any patient undergoing this type of operation must be followed indefinitely in order to detect any potential neoplastic changes in the small segment of remaining mucosa.

The median stool frequency of 6 per 24 hours 1 year after surgery in our patients compares favorably with that reported by other authors. In addition, this is quite similar to the frequencies reported with the $S$-shaped reservoir, the $J$-shaped reservoir, and the lateral ileal reservoir. The differences in stool frequency between the straight endorectal pullthrough and the pullthrough done with a reservoir appear to occur during the first year when the stool frequency seems to be significantly less with the reservoir. However, the disadvantages of the reservoir, such as the development of pouchitis, inability to evacuate, a longer and technically more difficult operation, and increased compromise of the blood supply to the ileo-anal anastomosis, all must be weighed against the inconvenience of an increased stool frequency during the first year after surgery. It seems to me that the most reasonable solution to this problem is the technique of balloon dilatation described by Telander [76]. My only concern with this technique is that the daily rectal dilatations may be psychologically traumatizing to a patient who is already emotionally traumatized by the basic disease.

Although the total proctocolectomy is an excellent operation for the definitive management of ulcerative colitis and familial polyposis, many patients are emotionally disturbed by the presence of an abdominal stoma. This often results in a significant delay in surgery. The endorectal pullthrough has the advantage of offering the patient with ulcerative colitis and familial polyposis proper treatment of the basic disease together with a more 
acceptable lifestyle. All but 6 patients preferred the operation to a permanent ileostomy in spite of the fact that several experienced a relatively high stool frequency. The presence of fecal continence is probably the most important factor in patient satisfaction. If the operation is done properly, incontinence should not occur. The results in this series of patients have encouraged us to continue to recommend this approach to children and adults with ulcerative colitis and familial polyposis. If a patient is not anxious to have the endorectal pullthrough procedure done at the time of colectomy, or if the surgeon is not experienced in doing this procedure, we strongly recommend that a subtotal colectomy together with a mucous fistula of the sigmoid colon and an end ileostomy be performed so that a pullthrough procedure can be done at a later date if desired by the patient.

\section{Résumé}

La colite ulcéreuse reste une affection redoutable chez l'enfant et le jeune adulte. Malgré un traitement médical intense par la sulfasalazine et les corticoïdes la majorité des malades atteints de colite ulcéreuse diffuse devront subir une colectomie totale. L'opération standard, la coloprotectomie avec iléostomie terminale permanente reste probablement la meilleure méthode de traitement de cette affection car elle permet l'exérèse totale des lésions; cependant l'iléostomie peut être à l'origine d'un sévère traumatisme psychologique. Pour l'éviter les opérations respectant l'appareil sphinctérien ont été tentées dès 1933 mais avec un succès relatif jusqu'en 1977 moment ou se manifeste un nouvel intérêt pour l'abaissement endorectal de l'iléon. Depuis cette époque de multiples centres dans le monde lui ont donné la préférence que l'abaissement transanal s'accompagne ou non de la constitution d'un réservoir iléal. Bien que le réservoir iléal présente certains avantages sa constitution délicate s'accompagne de nombreuses complications. L'expérience de l'Université de Michigan concernant l'abaissement iléal transanal appliqué au traitement de la colite ulcéreuse et de la polypose familiale pendant la période s'étendant de 1977 à 1984 est rapportée par les auteurs. Tous les malades ainsi traités sont continents, le nombre moyen des selles par 24 heures s'élevant à 6 . La satisfaction éprouvée par la majorité des opérés est supérieure à celle des malades qui ont subi une coloprotectomie totale avec iléostomie classique. A partir de ces faits, il est possible d'affirmer que l'exérèse globale du rectum et du colon avec abaissement transanal de l'iléon est l'opération de choix.

\section{Resumen}

La colitis ulcerativa sigue siendo una enfermedad devastadora para el niño y el adulto joven. A pesar de terapia médica intensa con sulfasalazina y corticosteroides, la mayoría de los pacientes con colitis ulcerativa universal, a la larga, requieren colectomía total. La operación estandar de proctocolectomía total e ileostomía permanente todavía es, probablemente, el mejor procedimiento para el manejo definitivo de esta enfermedad en virtud de que la totalidad del tejido enfermo puede ser removido mediante la operación; sinembargo, el estoma abdominal resultante puede crear un trauma psicológico significativo en muchos de estos pacientes. Para resolver este problema, en 1933 fueron introducidos los procedimientos de conservación de esfínter, los cuales apenas fueron marginalmente exitosos hasta 1977, cuando se desarrolló un renovado interés en los procedimientos endorrectales de "pullthrough." Desde tal época algunos centros de diversos lugares del mundo han llegado a tener suficiente experiencia con el procedimiento endorrectal, con o sin el uso de reservorio ileal. Aun cuando el reservorio ileal parece poseer ciertas ventajas sobre el simple procedimiento de "pullthrough," la operación también se halla asociada con un número importante de complicaciones y significa un ejercicio quirúrgico técnicamente bastante más complicado.

En el presente trabajo se informa la experiencia de la Universidad de Michigan con el procedimiento simple de "pullthrough" en pacientes con colitis ulcerativa y poliposis familiar durante el periodo comprendido entre 1977 y 1984. Todos los pacientes en nuestra serie se encuentran continentes y exhiben un promedio de 6 deposiciones en las 24 horas un año después de la operación. El grado de satisfacción de los pacientes es excelente, con la mayoría manifestando preferencia en cuanto a la calidad de su vida sin ileostomía. En el momento actual nosotros recomendamos vehementemente el procedimiento endorrectal de "pullthrough" para todo paciente con colitis ulcerativa.

\section{References}

1. Corbett R.S.: Review of surgical treatment of chronic ulcerative colitis: President's address. Proc. R. Soc. Med. 38:277, 1945

2. Brown, J.Y.: Value of complete physiological rest of large bowel in ulcerative and obstructive lesions. Surg. Gynecol. Obstet. 16:610, 1913

3. Cattell, R.B.: Surgical treatment of ulcerative colitis. Gastroenterology 10:63, 1948

4. Goligher, J.C.: Primary excisional surgery in treatment of ulcerative colitis. Ann. R. Coll. Surg. Engl. $15: 316,1954$ 
5. Brooke, B.N.: The management of an ileostomy including its complications. Lancet 2:102, 1952

6. Aylett, S.O.: Three hundred cases of diffuse ulcerative colitis treated by total colectomy and ileo-rectal anastomosis. Br. Med. J. 1:1001, 1966

7. Kock, N.G., Darle, N., Hulten, L., et al.: Ileostomy. Curr. Prob. Surg. 14:1, 1977

8. Beahrs, O.H.: Use of ileal reservoir following proctocolectomy. Surg. Gynecol. Obstet. 141:363, 1975

9. Beahrs, O.H., Adson, M.A.: Ileal pouch with ileostomy rather than ileostomy alone. Am. J. Surg. 125:154, 1973

10. Beahrs, O.H., Kelly, K.A., Adson, M.A., Chong, G.C.: Ileostomy with ileal reservoir rather than ileostomy alone. Ann. Surg. 179:634, 1974

11. Dozois, R.R., Kelly, K.A., Ilstrup, D., Beart, R.W., Jr., Beahrs, O.N.: Factors affecting revision rate after continent ileostomy. Arch. Surg. 116:610, 1981

12. Kelly, K.A.: Ileostomy-continent or incontinent? Curr. Concepts Gastroenterol. 4:22, 1979

13. Kock, K.A.: Intra-abdominal "reservoir"' in patients with permanent ileostomy; preliminary observations on a procedure resulting in fecal "continence" in five ileostomy patients. Arch. Surg. 99:223, 1969

14. Kock, N.G.: Continent ileostomy. Prog. Surg. 12:180, 1973

15. Kock, N.G.: Present status of the continent ileostomy; surgical revision of the malfunctioning ileostomy. Dis. Colon Rectum 19:200, 1976

16. Kock, N.G., Darle, N., Kewenter, J., Myrvold, H., Philipson, B.: The quality of life after proctocolectomy and ileostomy: A study of patients with conventional ileostomies converted to continent ileostomies. Dis. Colon Rectum 17:287, 1974

17. Nissen, R.: Demonstrationen aus der operativen Chirurgie Zunachst einige Beobachtungen aus der plastischen chirurgie. Zentralbl. Chir. 60:883, 1933

18. Wangensteen, O.H.: Primary resection (closed anastomosis) of the colon and rectosignoid; including description of abdomino-anal methods for restoration of continuity accompanying excision of carcinoma of the rectal ampulla. Surgery 14:403, 1943

19. Ravitch, M.M., Sabiston, D.C., Jr.: Anal ileostomy with preservation of the sphincter: A proposed operation in patients requiring total colectomy for benign lesions. Surg. Gynecol. Obstet. 84:1095, 1947

20. Ravitch, M.M.: Anal ileostomy with sphincter preservation in patients requiring total colectomy for benign conditions. Surgery 24:170, 1948

21. Ravitch, M.M., Handelsman, J.C.: One stage resection of entire colon and rectum for ulcerative colitis and polypoid adenomatosis. Bull. Johns Hopkins Hosp. 88:59, 1951

22. Babcock, W.W.: In Anus, rectum, sigmoid colon: Diagnosis and treatment, H.E. Bacon, editor. Philadelphia, J.B. Lippincott, Co., 1949

23. Payne, H.: In Anus, rectum, sigmoid colon: Diagnosis and treatment, H.E. Bacon, editor. Philadelphia, J.B. Lippincott Co., 1949

24. Hay, D.: In Anus, rectum, sigmoid colon: Diagnosis and treatment, H.E. Bacon, editor. Philadelphia, J.B. Lippincott, 1949

25. Casanova-Diaz, A.S.: Construction of pouch using "pantaloon" technic for pull-through of ileum follow- ing total colectomy: Report of experiment work and results. Am. J. Surg. 90:742, 1955

26. Best, R.R.: Evaluation of ileoproctostomy to avoid ileostomy in various colon lesions. J.A.M.A. 150:637, 1952

27. Devine, J., Webb, R.: Resection of the rectal mucosa, colectomy and anal ileostomy with normal continence. Surg. Gynecol. Obstet. 92:437, 1951

28. Schneider, S.: Anal ileostomy: Experiences with a new three-stage procedure. Arch. Surg. 70:539, 1955

29. Gaston, E.A.: Fecal continence following resections of various portions of the rectum with preservation of the anal sphincters. Surg. Gynecol. Obstet. 87:669, 1948

30. Goligher, J.C.: The functional results after sphinctersaving resections of the rectum. Ann. R. Coll. Surg. Engl. 8:421, 1951

31. Griffen, W.O., Jr., Lillehei, R.C., Wangensteen, O.H.: Ileoproctostomy in ulcerative colitis: Longterm follow-up, extending in early cases to more than 20 years. Surgery 53:705, 1963

32. Wangensteen, O.H., Toon, R.W.: Primary resection of the colon and rectum with particular reference to cancer and ulcerative colitis. Am. J. Surg. 75:384, 1948

33. Drobni, S.: One-stage proctocolectomy and anal ileostoy: Report of 35 cases. Dis. Colon. Rectum 10:443, 1967

34. Drobni, A.: One-stage proctocolectomy with anal ileostomy. Dis. Colon Rectum 7:416, 1964

35. Pomerantz, M., Sabiston, D.C., Jr.: Modified operation for the treatment of Hirschsprung's disease. Am. J. Surg. 115:198, 1968

36. Safaie-Shirazi, S., Soper, R.T.: Endorectal pullthrough procedure in the surgical treatment of familial polyposis coli. J. Pediatr. Surg. 8:711, 1973

37. Martin, L.W., LeCoultre, C., Schubert, W.K.: Total colectomy and mucosal proctectomy with preservation of continence in ulcerative colitis. Ann. Surg. $186: 477,1977$

38. Fonkalsrud, E.W.: Endorectal ileoanal anastomosis with isopenstaltic ileal reservoir after colectomy and mucosal proctectomy. Ann. Surg. 199:151, 1984

39. Parks, A.G., Nicholls, R.J.: Proctocolectomy without ileostomy for ulcerative colitis. Br. Med. J. 2:85, 1978

40. Fonkalsrud, E.W.: Total colectomy and endorectal ileal pull-through with internal ileal reservoir for ulcerative colitis. Surg. Gynecol. Obstet. 150:1, 1980

41. Peck, D.A.: Rectal mucosal replacement. Ann. Surg. $191: 294,1980$

42. Utsunomiya, J., Iwama, T., Imajo, M., Matsuo, S., Sawai, S., Yaegashi, K., Hirayama, R.: Total colectomy, mucosal proctectomy, and ileoanal anastomosis. Dis. Colon rectum 23:459, 1980

43. Telander, R .L., Perrault, J.: Total colectomy with rectal mucosectomy and ileoanal anastomosis for chronic ulcerative colitis in children and young adults. Mayo Clin. Proc. 55:420, 1980

44. Coran, A.G., Sarahan, T.M., Dent, T.L., FiddianGreen, R., Wesley, J.R., Jordan, F.T.: The endorectal pull-through for the management of ulcerative colitis in children and adults. Ann. Surg. 197:99, 1983

45. Rothenberger, D.A., Vermeulen, F.D., Christenson, 
C.E., Balcos, E.G., Nemer, F.D., Goldberg, S.M., Belliveau, P., Nivatvongs, S., Schottler, J.L., Fang, D.T., Kennedy, H.L.: Restorative proctocolectomy with ileal reservoir and ileoanal anastomosis. Am. J. Surg. 145:82, 1983

46. Devroede, G.J., Dockerty, M.B., Sauer, W.G., et al.: Cancer of the colon in patients with ulcerative colitis since childhood. Can. J. Surg. 15:369, 1972

47. Devroede, G.J., Taylor, W.F., Sauer, W.G., Jackman, R.J., Stickler, G.B.: Cancer risk and life expectancy of children with ulcerative colitis. N. Engl. J. Med. 285:17, 1971

48. Telander, R.L., Perrault, J.: Colectomy with rectal mucosectomy and ileoanal anastomosis in young patients: Its use for ulcerative colitis and familial polyposis. Arch. Surg. 116:623, 1981

49. Dimitrium, V.: Formation of artificial rectum by transplantation of piece of ileum. Spitalul. 48:97, 1928

50. Martin, L.W., Fischer, J.E.: Preservation of anorectal continence following total colectomy. Ann. Surg. 196:700, 1982

51. Fonkalsrud, E.W.: Endorectal ileal pull-through with lateral ileal reservoir for benign colorectal disease. Ann. Surg. 194:761, 1981

52. Stephens, E.D., Smith, E.D.: Ano-rectal malformations in children. Chicago, Year Book Medical Pub, 1971

53. Kiesewetter, W.B., Nixon, H.H.: Imperforate anus-I, its surgical anatomy. J. Pediatr. Surg. 2:60, 1967

54. Schuster, M.M.: Motor action of rectum and anal sphincters in continence and defecation. In Handbook of physiology, C.F. Code, editor. Washington, D.C., American Physiological Society, 1968

55. Gaston, E.A.: The physiology of fecal continence. Surg. Gynecol. Obstet. 87:280, 1948

56. Gaston, E.A.: Physiologic basis for preservation of fecal continence after resection of the rectum. J.A.M.A. 146:1486, 1951

57. Goligher, J.C., Hughes, E.S.R.: Sensibility of the rectum and colon: Its role in the mechanism of anal continence. Lancet $1: 543,1951$

58. Lane, R.H.S., Parks, A.G.: Function of the anal sphincters following colo-anal anastomosis. Br. J. Surg. 64:596, 1977

59. Duthie, H.L., Gairns, F.W.: Sensory nerve-endings and sensation in the anal region of man. Br. J. Surg. $47: 585,1960$

60. Phillips, S.F., Edwards, D.A.W.: Some aspects of anal continence and defecation. Gut 6:396, 1965

61. Heppell, J., Kelly, K.A., Phillips, S.F., Beart, R.W., Jr., Telander, R.L., Perrault, J.: Physiologic aspects of continence after total colectomy, mucosal proctectomy and endorectal ileo-anal anastomosis. Ann. Surg. 195:435, 1982

62. Von Ekesparre, W., Janneck, C.: Follow-up results of the pull-through operation for ulcerative colitis in children. Prog. Pediatr. Surg. 11:7, 1978

63. Wolfstein, I.H., Dreznik, Z.J., Avigad, I.S.: Total colectomy and anal ileostomy in multiple polyposis coli. Arch. Surg. 113:1101, 1978

64. Heimann, T., Beck, A.R., Greenstein, A.J.: Familial polyposis coli: Management by total colectomy with preservation of continence. Arch. Surg. 113:1104, 1978

65. Di Falco, G., D’Agata, G.: Anal ileostomy in multiple polyposis. Am. J. Surg. 138:456, 1979

66. Parks, A.G., Nicholls, R.J., Belliveau, P.: Proctocolectomy with ileal reservoir and anal anastomosis. Br. J. Surg. 67:533, 1980

67. Glotzer, D.J., Sharma, A.N.: Experimental total abdominoperineal colectomy with preservation of the sphincters. Surg. Gynecol. Obstet. 119:338, 1964

68. Pemberton, J.H., Heppell, J., Beart, R.W., Jr., Dozois, R.R., Telander, R.L.: Endorectal ileoanal anastomosis. Surg. Gynecol. Obstet. 155:417, 1982

69. Handelsman, J.C., Fishbein, R.H., Hoover, H.C., Jr., Smith, G.W., Haller, J.A., Jr.: Endorectal pullthrough operation in adults after colectomy and excision of rectal mucosa. Surgery 93:247, 1983

70. Heimann, T., Gelernt, I., Bauer, J., Salky, B., Bleicher, M., Beck, A.R., Kreel, I.: Mucosal proctectomy without reservoir. Am. J. Surg. 145:674, 1983

71. Taylor, B.M., Beart, R.W., Jr., Dozois, R.R., Kelly, K.A., Phillips, S.F.: Straight ileoanal anastomosis vs. ileal pouch-anal anastomosis after colectomy and mucosal proctectomy. Arch. Surg. 118:696, 1983

72. Roediger, W.E.W., Pihl, E., Hughes, E.: Preserving the ascending colon as an alternative surgical option in ulcerative colitis. Surg. Gynecol. Obstet. 154:348, 1982

73. Coran, A.G., Weintraub, W.H.: Modification of the endorectal procedure for Hirschsprung's disease. Surg. Gynecol. Obstet. 143:277, 1976

74. Jordan, F.T., Coran, A.G., Weintraub, W.H., et al.: An evaluation of the modified endorectal procedure for Hirschsprung's disease, J. Pediatr. Surg. 14:681, 1979

75. Jordan, F.T., Coran, A.G., Wesley, J.R.: Modified endorectal procedure for management of longsegment aganglionosis. Ann. Surg. 194:70, 1981

76. Telander, R.L., Perrault, J., Hoffman, A.D.: Early development of the neorectum by balloon dilatations after ileoanal anastomosis. J. Pediatr. Surg. 16:911, 1981 